\title{
Thermogravimetric-mass spectrometric study on the evolution of nitrogen compounds during coal devolatilisation
}

\author{
A. Arenillas, F. Rubiera, C. PeVidA and J.J. Pis* \\ Instituto Nacional del Carbón (CSIC). Department of Energy \& Environment. \\ Apartado 73, 33080 Oviedo, Spain.
}

\begin{abstract}
Emissions of nitrogen oxides during coal combustion are a major environmental problem. The chemically bound nitrogen in fuel accounts for up to $80 \%$ of total NOx emissions. In this respect, fundamental studies are needed to clarify the mechanisms and to identify the different species that are precursors in the formation of the NOx. Mass spectrometry (MS) has been used for decades as a successful technique in evolved gas analysis. However, MS is normally used to identify typical volatile compounds formed during coal pyrolysis (i.e. $\mathrm{H}_{2}, \mathrm{CH}_{4}, \mathrm{CO}$, $\mathrm{CO}_{2}$ and $\mathrm{H}_{2} \mathrm{O}$ ) but very few works on the detection by MS of nitrogen compounds during coal devolatilisation can be found. In this work, the possibility of detecting different nitrogen compounds by means of TG-MS during the temperature-programmed pyrolysis of coal was evaluated. Interferences in the N-compounds MS signals were determined. The use of model compounds provided additional information on the MS response factors of the volatile compounds produced.
\end{abstract}

Key words: Coal devolatilisation; TG-MS; nitrogen volatile compounds; model compounds.

\section{INTRODUCTION}

Far from being just a mere step in the overall combustion reaction, devolatilisation has a marked influence throughout the life of the solid coal particles in the furnace. Volatiles released during devolatilisation can account for up to half of the original coal mass, 
significantly increasing the temperature surrounding the particles in a relatively short length of time, due to the gas phase combustion of volatiles. In addition, the distribution of fuel nitrogen among the devolatilisation products (char, tar and gases) is also influenced by the operating conditions [1-2].

Fuel-NO constitutes the largest portion ( $80 \%)$ of total NO emissions (volatile-NO and charNO) in modern pf coal combustion boilers, and in fluidised bed combustion fuel-NO accounts for the whole of the nitrogen oxide emissions [3]. The fate of coal nitrogen during combustion has been studied by several researchers, but no simple relation between coal nitrogen and nitric oxide evolved during combustion has been found [5-7]. An intensive effort has been directed at elucidating the mechanism of fuel-NO formation through coal nitrogen compounds [8-10]. Nevertheless, the problem remains unsolved, mainly due to a complex combination of factors that affect the final NO formation.

Devolatilisation conditions affect not only the distribution of nitrogen in char, tar and gases, but also potential secondary reactions, which are homogeneous in the gas phase and heterogeneous with the char. Thus the final distribution of the so-called NOx precursor compounds is also affected. A simplified scheme of nitrogen distribution during devolatilisation is shown in Figure 1.

The increase in temperature causes bond breaking, and the nitrogen is split into char-, tar- and some volatile-N. The usual nitrogen gaseous compounds formed at this stage are mainly HCN and $\mathrm{NH}_{3}$, which are considered as the main NOx precursor compounds [11]. The volatile nitrogen fractions such as $\mathrm{HCN}$ and $\mathrm{NH}_{3}$, depend on several parameters including the temperature, heating rate, pressure and residence time of the fuel in the reactor, as well as the 
devolatilisation rate and fuel composition [12]. Some authors [13-14] suggest that $\mathrm{NH}_{3}$ is mainly produced in secondary reactions involving $\mathrm{HCN}$, but it is not clear whether these reactions occur via gas or gas-solid phase. The source of the hydrogen atoms is also unknown. Further tar cracking during devolatilisation can produce, in addition to $\mathrm{HCN}$ and $\mathrm{NH}_{3}$, other nitrogen compounds such as $\mathrm{N}_{2}, \mathrm{~N}_{2} \mathrm{O}$ and $\mathrm{NO}$ through several, still not very well defined, homogenous and heterogeneous reactions.

In the abatement of NO formation, a more complete understanding of the behaviour of $\mathrm{N}$ components during the course of coal devolatilisation and coal combustion is of great importance. Therefore, further work on the detection of nitrogen volatile compounds during the devolatilisation step is needed in order to propose possible $\mathrm{N}_{2} \mathrm{O}$ or $\mathrm{NO}$ formation mechanisms. In this study, different nitrogen volatile compounds released from coal devolatilisation were analysed by means of a TG-MS system.

TG pyrolysis experiments have been extensively used for coal characterisation [15-21]. Most of them determine weight loss and characteristic temperatures; others also analyse the evolved gases by means of infrared spectroscopy (IR), gas chromatography (GC) or mass spectrometry (MS). Usually, the volatile species analysed are $\mathrm{H}_{2}, \mathrm{CH}_{4}, \mathrm{H}_{2} \mathrm{O}, \mathrm{CO}$ and $\mathrm{CO}_{2}$, these being the most abundant in coal devolatilisation [22-23].

The concern about the evolution of nitrogen compounds during coal devolatilisation is more recent. Most of the works on coal devolatilisation including the detection of nitrogen volatile compounds were performed in reactors different to TG. Moreover, the evolved nitrogen compounds are usually detected by GC or IR [2, 14, 24-25]. Very few works on N- 
compounds evolution during coal devolatilisation followed by MS can be found, while even fewer employed TG-MS.

Herrera et al. [26] employed TG-MS for detecting nitrogen compounds $\left(\mathrm{NH}_{3}, \mathrm{HCN}\right)$ during thermal decomposition of aliphatic polyamides. However, the behaviour of these compounds during pyrolysis is different to that of coal. Ehrburger et al. [27] investigated the evolution of nitrogen compounds ( $\mathrm{HCN}, \mathrm{NH}_{3}, \mathrm{~N}_{2}, \mathrm{NO}$ ) by $\mathrm{MS}$, in a fixed bed reactor, during the temperature-programmed desorption of active carbons. Boudou et al. [28] used MS to study the evolution of different compounds, including $\mathrm{N}_{2}$, during the pyrolysis of a bituminous coal modified by selective chemical reactions. In this case, the detection by MS was performed not directly but after setting some specific traps.

Although each method provides valid information, the use of TG-MS has many advantages. The main one is that two types of analyses (thermogravimetric and evolved gas analysis) can be performed at the same time, which can be a very helpful tool in the study of coal behaviour during devolatilisation and/or combustion. Kopp et al. [29], used TG-MS during coal pyrolysis and combustion tests. They assigned the $\mathrm{m} / \mathrm{z} 14$ signal to $\mathrm{N}^{+}$, without additional comments. Matuschek et al. [30] suggested that $\mathrm{m} / \mathrm{z} 27$ might belong to $\mathrm{HCN}^{+}$or aliphatic fragments $\left(\mathrm{C}_{2} \mathrm{H}_{3}{ }^{+}\right)$. Comparison between this signal and $\mathrm{m} / \mathrm{z} 41$, which is due to light hydrocarbons $\mathrm{C}_{3} \mathrm{H}_{5}{ }^{+}$, resulted in the assignment of $\mathrm{m} / \mathrm{z} 27$ to $\mathrm{HCN}^{+}$between $400-600^{\circ} \mathrm{C}$. Additional studies on N-compounds during coal devolatilisation by TG-MS can be found in the works of Thomas research group [31-32]. However, most of the results correspond to combustion and in the parts that consider coal devolatilisation, the gas sampling was carried out at the exit of the TG. They assigned $\mathrm{m} / \mathrm{z} 14,27$ and 30 to $\mathrm{N}_{2}^{++}, \mathrm{HCN}^{+}$and $\mathrm{NO}^{+}$, 
respectively, although they mentioned that some contributions from light hydrocarbons should not be excluded. These contributions, however, were not quantified.

In this work, the evolution of gaseous species during coal devolatilisation was followed by using TG-MS. Due to the difficulties involved in the detection of nitrogen compounds during coal devolatilisation by TG-MS, and the small number of works published on this subject, the main aim of this work was to evaluate the applicability of TG-MS for following nitrogen volatile species during the devolatilisation of coal. The contributions of other volatile compounds to the $\mathrm{m} / \mathrm{z}$ signals assigned to nitrogen compounds were also evaluated. The use of model compounds provided further information about the MS response factors of some volatile species.

\section{EXPERIMENTAL}

Temperature-programmed pyrolysis experiments were performed in a thermobalance (TG), where $2 \mathrm{mg}$ of sample was placed in a platinum crucible and heated at $15^{\circ} \mathrm{C} \mathrm{min}{ }^{-1}$ from room temperature to $850^{\circ} \mathrm{C}$, under an argon flow rate of $50 \mathrm{~mL} \mathrm{~min}^{-1}$.

A quadrupole mass spectrometer (MS) linked to the thermobalance was used to record the gas evolution profiles. To avoid secondary reactions a probe was placed very close to the sample crucible of the thermobalance in the direction of the gas flow. A representative portion of the volatile products was introduced into the ion source of the mass spectrometer through a heated transfer line. Electron impact ionisation was applied with $100 \mathrm{eV}$ electron energy. The ion signals given by the spectrometer were normalised by the total intensity and the sample mass to make the results internally consistent. The repeatability of the profiles was excellent, and a statistic study of the integrated peak area values was performed, using Student`s t-test, 
giving a very good precision [33]. In this way, it was possible to compare the same $\mathrm{m} / \mathrm{z}$ signals for different samples and perform a semi-quantitative analysis of the evolved gaseous compounds.

It is important to note that a pyrolysate produced at a high heating rate is rich in high molecular weight compounds, whereas the thermogravimetric analysis results in higher amounts of low molecular weight products. Moreover, one mass unit is likely to be formed from more than one compound. Therefore in many cases only the fragment ions detected by the mass spectrometer can be specified [23]. Although tar is an important source of Ncompounds, its relative contribution was not quantified in this work because no separation of tar and gas in the TG system was attempted. In order to avoid condensation of the vapours, all possible cold points were heated (i.e. the connection between the TG and the MS).

Several MS signals (m/z 2, 12, 14, 15, 16, 17, 18, 26, 27, 28, 30, 41 and 44) were monitored in order to follow the evolution of the most representative volatile compounds such as light hydrocarbons, $\mathrm{CO}, \mathrm{CO}_{2}, \mathrm{H}_{2} \mathrm{O}, \mathrm{H}_{2}$, and nitrogen compounds $\left(\mathrm{N}_{2}, \mathrm{HCN}, \mathrm{NH}_{3}, \mathrm{NO}\right.$ and $\left.\mathrm{N}_{2} \mathrm{O}\right)$.

For the assignment of the $\mathrm{m} / \mathrm{z}$ signals, different MS libraries were consulted and some discrepancies were found. Moreover, differences were also observed between the literature and tests carried out on pure gases in the spectrometer used in this study. Taking into account these variations, the assignment of the registered $\mathrm{m} / \mathrm{z}$ signals to the fragmented ions are presented in Table 1. It has to be noted that some of the species were not included in this table (i.e. $\mathrm{m} / \mathrm{z} 18$ due to $\mathrm{CO}, \mathrm{CO}_{2}$, NO) due to their very low intensity, caused by isotopes (i.e. ${ }^{18} \mathrm{O}^{+}$) or by the tails of the main $\mathrm{m} / \mathrm{z}$ signal. It can be observed that most of the $\mathrm{m} / \mathrm{z}$ signals detected can be assigned to more than one fragmented ion. Due to the higher concentration 
and higher MS response factor, traditionally $\mathrm{m} / \mathrm{z} 18,28$ and 44 have been assigned to $\mathrm{H}_{2} \mathrm{O}$, $\mathrm{CO}$ and $\mathrm{CO}_{2}$, respectively. There are other minor contributions to these signals, that can be neglected without much error.

The detection of $\mathrm{NH}_{3}$ cannot be performed by MS, due to the interference of $\mathrm{H}_{2} \mathrm{O}$ in its main $\mathrm{m} / \mathrm{z}$ signals (i.e. $\mathrm{m} / \mathrm{z} 17$ and 18). Besides, $\mathrm{H}_{2} \mathrm{O}$ is evolved in much greater amounts than $\mathrm{NH}_{3}$ during coal devolatilisation. However, as already mentioned, $\mathrm{NH}_{3}$ is mainly formed from secondary reactions, but due to the TG-MS coupling system used, in which the probe is located very close to the sample, these reactions are avoided. The signals of $\mathrm{N}$-compounds at $\mathrm{m} / \mathrm{z}$ 14, 27 and 30, also show interferences from other species. It was observed in this work that $\mathrm{CO}$ contributes to the first two signals due to $\mathrm{CO}^{++}(\mathrm{m} / \mathrm{z} 14)$ and the tail of its main signal to $\mathrm{m} / \mathrm{z} 27$. These interferences can be evaluated and corrected by conducting tests with MS on the interfering gases (i.e. $\mathrm{CO}$ and $\mathrm{CH}_{4}$ on $\mathrm{m} / \mathrm{z}$ 14), as will be shown below. On the other hand, $\mathrm{CO}_{2}$ and $\mathrm{N}_{2} \mathrm{O}$ have the same main signal $(\mathrm{m} / \mathrm{z} 44)$, like $\mathrm{CO}$ and $\mathrm{N}_{2}(\mathrm{~m} / \mathrm{z} 28)$. Thus the detection of the reduced species (i.e. $\mathrm{N}_{2}$ and $\mathrm{N}_{2} \mathrm{O}$ ) has to be followed with another $\mathrm{m} / \mathrm{z}$ signal, different from the main one. Generally $\mathrm{m} / \mathrm{z} 14$ is used for the study of the nitrogen reduced species [32].

The possibility of interferences in $\mathrm{m} / \mathrm{z} 27$ and 30, from light hydrocarbons should also be considered. The high number of possible light hydrocarbons $\left(\mathrm{C}_{2} \mathrm{H}_{4}, \mathrm{C}_{2} \mathrm{H}_{6}, \mathrm{C}_{3} \mathrm{H}_{6}, \mathrm{C}_{3} \mathrm{H}_{8}\right.$, etc. $)$ and the crossed contributions of their $\mathrm{m} / \mathrm{z}$ signals, makes it very difficult to calculate the interferences. Thus, the use of model compounds with and without nitrogen in their composition can provide information about the relative importance (i.e. response factors) of light hydrocarbons for the $\mathrm{m} / \mathrm{z} 27$ and 30, compared with that of $\mathrm{N}$-compounds. 


\section{RESULTS AND DISCUSSION}

MS interference calculations

In order to calculate the contributions of the different volatile compounds to the MS signals, various detection tests were performed. In these tests the mass spectra of high purity gases diluted in Ar were registered by the MS, which was run in the scan mode. The gases evaluated and their main m/z signals were: $\mathrm{CH}_{4}(\mathrm{~m} / \mathrm{z} 16)$, $\mathrm{CO}(\mathrm{m} / \mathrm{z} 28), \mathrm{CO}_{2}(\mathrm{~m} / \mathrm{z} 44), \mathrm{N}_{2}$ (m/z 28), $\mathrm{N}_{2} \mathrm{O}(\mathrm{m} / \mathrm{z} 44)$ and $\mathrm{NO}(\mathrm{m} / \mathrm{z} 30)$. These main signals were given a value of 100 , and the rest of the signals for each compound were calculated as a percentage of the main signal. The $\mathrm{m} / \mathrm{z}$ signals detected and their relative intensities for each evaluated compound are presented in Table 2. It should be noted that $\mathrm{m} / \mathrm{z}$ signals displaying relative intensity values lower than $1 \%$ were neglected.

The gaseous compounds $\mathrm{H}_{2}, \mathrm{H}_{2} \mathrm{O}, \mathrm{CO}$ and $\mathrm{CO}_{2}$ were followed via their main m/z signals $(\mathrm{m} / \mathrm{z}$ 2, 18, 28 and 44, respectively), there being negligible contributions from other compounds. $\mathrm{CH}_{4}$ was followed via m/z 15 to avoid contributions from oxygen to its main signal (m/z 16). The contribution of NO to $\mathrm{m} / \mathrm{z} 15$ (as the ${ }^{15} \mathrm{~N}^{+}$isotope) can be neglected, as can be seen in Table 2. The high concentration of $\mathrm{CH}_{4}$ compared with that of NO in coal devolatilisation, along with the small contribution of NO to $\mathrm{m} / \mathrm{z} 15$, in the form of the ${ }^{15} \mathrm{~N}^{+}$isotope (cf. Table 2), also justify the choice of m/z 15 for following the evolution of $\mathrm{CH}_{4}$.

The evolution of $\mathrm{N}_{2}$ and $\mathrm{N}_{2} \mathrm{O}$ was followed at $\mathrm{m} / \mathrm{z} 14$, instead of at their main signals to avoid contributions from $\mathrm{CO}$ and $\mathrm{CO}_{2}$, respectively. $\mathrm{HCN}$ and $\mathrm{NO}$ were followed via their main signals, m/z 27 and 30, respectively. Consequently, in this work the m/z signals chosen to follow nitrogen compounds during coal devolatilisation were m/z 14, 27 and 30. However, some corrections must be applied to these signals. 
Contributions to m/z 14 were detected from $\mathrm{N}_{2}, \mathrm{~N}_{2} \mathrm{O}, \mathrm{NO}, \mathrm{CH}_{4}$ and $\mathrm{CO}$; those due to $\mathrm{CH}_{4}$ and CO were evaluated as a percentage of m/z 15 and 28 (17 and $1 \%$, respectively). The small contribution of $\mathrm{NO}$ cannot be evaluated as a percentage of $\mathrm{m} / \mathrm{z} 30$, because $\mathrm{N}_{2} \mathrm{O}$ also contributes to $\mathrm{m} / \mathrm{z} 30$. Thus after the corrections due to $\mathrm{CH}_{4}$ and $\mathrm{CO}, \mathrm{m} / \mathrm{z} 14$ were used to follow the evolution of the reduced species $\left(\mathrm{N}_{2}\right.$ and $\left.\mathrm{N}_{2} \mathrm{O}\right)$, with negligible contributions from other compounds.

The main signal of $\mathrm{HCN}(\mathrm{m} / \mathrm{z} 27)$ receives a contribution from CO (1 \% of m/z 28), and a small contribution from $\mathrm{N}_{2}$ as a tail of its main signal (m/z 28). The signal m/z 30 showed contributions from $\mathrm{NO}$ and $\mathrm{N}_{2} \mathrm{O}$, although the one due to $\mathrm{N}_{2} \mathrm{O}$ can be neglected, because with the MS sampling system, which prevents secondary reactions from taking place, $\mathrm{N}_{2} \mathrm{O}$ is not produced, as will be shown later. In this work, no contribution was detected from the isotope of $\mathrm{CO},{ }^{12} \mathrm{C}^{18} \mathrm{O}$, in contrast with the findings of other authors [34]. Thus, the following corrections were applied to the intensities given by the MS at m/z 14 and 27:

$\mathrm{N}_{2}$ and $\mathrm{N}_{2} \mathrm{O}$ evolution: $\mathrm{m} / \mathrm{z} 14-(0.01 \times \mathrm{m} / \mathrm{z} 28)-(0.17 \times \mathrm{m} / \mathrm{z} 15)$

HCN evolution: m/z 27 - $(0.01 \times \mathrm{m} / \mathrm{z} 28)$

According to Table 1, some potential contributions of light hydrocarbons to m/z 27 and 30 probably occurred. These contributions will be discussed below.

\section{Evaluation of MS response factors}

In order to evaluate the influence of hydrocarbons on m/z 14, 27 and 30, which are used to follow the evolution of nitrogen volatile compounds, a model coal was prepared and the MS 
signals registered during the devolatilisation of the model coal and a high volatile bituminous coal, were compared.

The model coal with nitrogen in its composition (MCN) was obtained by mixing phenolformaldehyde resin (PFR), 46\%, with perylenetetracarboxilic acid dianhydride (PTC), 9\%, poly-vinylpyrrolidone (PVPI), 36\%, poly-4-vinylpyridine (P4VP), 1\%, and 9cyanoanthracene (CYAN), 8\%. The PFR and PTC constitute the carbon matrix [35-36], while PVPI and P4VP represent the most abundant nitrogen functionalities in coal, pyrrolic and pyridinic, respectively [37-38]. The evolution of HCN during pyrolysis was simulated with the incorporation of CYAN to the model coal. PFR has already been used to simulate the behaviour of the carbon matrix in coals [35; 39-40]. The PFR used in this study was synthesized in the laboratory [41], the other constituents being supplied by Aldrich. The mixture of these components (i.e. PFR, PTC, PVPI, P4VP, CYAN) was cured at moderate temperature $\left(425^{\circ} \mathrm{C}\right)$ in an inert atmosphere, in order to favour the formation of cross-links so as to simulate the structure of coal. The resultant cured mixture was denoted as model coal with nitrogen (MCN). The proximate and ultimate analyses of $\mathrm{MCN}$, and those of the coal (CA) that was used for comparative purposes, are presented in Table 3. It can be observed that the volatile matter content is very similar, as are the carbon, hydrogen and nitrogen contents. The main differences between MCN and CA are the ash and sulphur contents, which are negligible in the case of MCN, and the oxygen content, which is higher in the case of MCN.

During the devolatilisation experiments of the model coal, special attention was paid to the evolution of light hydrocarbons and nitrogen compounds. Usually, the evolution of light hydrocarbons is followed at $\mathrm{m} / \mathrm{z} 41$ [30, 32]. Figure 2 shows the profiles for $\mathrm{m} / \mathrm{z} 41$ during the devolatilisation of CA and MCN. It can be observed that the main peak of m/z 41 appears at 
the same temperature and the shape is very similar for both samples. The CA coal presents a minor secondary peak at around $350^{\circ} \mathrm{C}$ and a tail of the main peak at high temperature. The model coal presents a secondary peak at high temperature (around $700^{\circ} \mathrm{C}$ ). These small differences are due to the complexity of the coal structure and the difficulty of completely simulating coal behaviour with model compounds. However, the evolution of light hydrocarbons during devolatilisation is very similar in both samples. This is corroborated in Figure 3, where the evolution of hydrocarbons during the coal devolatilisation tests, analysed by a Fourier transformed infrared (FTIR) spectroscope connected on line with the TG, is presented. The $3100-2800 \mathrm{~cm}^{-1}$ region includes the most representative light hydrocarbons [42-43] (i.e. $\mathrm{CH}_{4}, \mathrm{C}_{2} \mathrm{H}_{4}, \mathrm{C}_{2} \mathrm{H}_{6}, \mathrm{C}_{3} \mathrm{H}_{8}, \mathrm{C}_{4} \mathrm{H}_{10}$, etc.). Figure 3 shows this region for the devolatilisation gases from coals $\mathrm{CA}$ and $\mathrm{MCN}$ at a temperature of around $450^{\circ} \mathrm{C}$. It can be seen that in both cases there is a very well-defined peak at $3020 \mathrm{~cm}^{-1}$, mainly due to $\mathrm{CH}_{4}$. The broad band between 3000 and $2800 \mathrm{~cm}^{-1}$ is due to a mixture of other hydrocarbons $\left(\mathrm{C}_{2} \mathrm{H}_{4}\right.$, $\mathrm{C}_{2} \mathrm{H}_{6}, \mathrm{C}_{3} \mathrm{H}_{8}, \mathrm{C}_{4} \mathrm{H}_{10}$, etc.). From Figures 2 and 3, it can be concluded that the evolution of light hydrocarbons is very similar in both samples.

Besides light hydrocarbons, $\mathrm{CO}$ is the main volatile compound evolved during coal devolatilisation that interferes with the $\mathrm{m} / \mathrm{z}$ signals of nitrogen compounds (see Table 1 ). The $\mathrm{m} / \mathrm{z} 28$ profile mainly represents CO evolution during the devolatilisation step. It can be seen in Figure 4 that the main $\mathrm{CO}$ peak appears at the same temperature $\left(550^{\circ} \mathrm{C}\right)$ and presents a similar shape for both samples (CA and MCN). There are small differences at high temperature, MCN presenting a secondary peak at around $700^{\circ} \mathrm{C}$ which does not appear in the profile of coal CA, or at least it is not as prominent as the one corresponding to MCN. This difference can be related to the higher oxygen content of MCN. The peak of the CA coal at 
around $800^{\circ} \mathrm{C}$ can be assigned to carbonates, that decompose at high temperature to give $\mathrm{CO}_{2}$, which also contributes to $\mathrm{m} / \mathrm{z} 28$.

To sum up, it seems clear that MCN represents coal behaviour during devolatilistion quite well, including the release of light hydrocarbons.

In order to study the contribution of light hydrocarbons to $\mathrm{m} / \mathrm{z} 27$ and 30, another model compound without nitrogen in its composition was synthesized. The mixture of model compounds was modified by excluding the nitrogen compounds (PVPI, P4VP and CYAN), and modifying the percentages of PFR and PTC to obtain a mixture which, after the curing step already mentioned, has a similar volatile matter content to that of MCN, but without nitrogen in its composition. This sample was denoted as model coal without nitrogen (MC). The proximate and ultimate analyses of MC are presented in Table 3.

The $\mathrm{m} / \mathrm{z}$ 14, 27 and 30 profiles were compared for the three samples (CA, MCN and MC). It should be pointed out that the $\mathrm{m} / \mathrm{z} 14$ profiles were negligible after the $\mathrm{CO}$ and $\mathrm{CH}_{4}$ corrections. This means that the nitrogen-reduced compounds are probably formed by secondary reactions, which are minimised in the TG-MS sampling system (MS probe close to the sample and in the gas flow direction). In order to validate this assumption, the connecting system was changed and the MS probe was situated at the TG exit. With this arrangement, there was a change in the evolution of volatile compounds, as can be seen in Figure 5, because the higher gas residence time favoured secondary reactions. It can be observed that when the MS probe is positioned inside the furnace (F), close to the sample, the $\mathrm{m} / \mathrm{z} 27$ and 30 profiles present a unique and well defined peak, whilst when the MS probe is located at the TG exit (E), the profiles present shoulders at high temperature due to secondary reactions. 
Regarding the $\mathrm{m} / \mathrm{z} 14$ profile, it can be observed that this only appears in the secondary reaction zone. Thus, it can be affirmed that with the TG-MS sampling system in which the MS probe is close to the sample, secondary reactions are avoided and no reduced species are detected.

The m/z 27 and 30 profiles that correspond to HCN and NO are presented, after correction of $\mathrm{m} / \mathrm{z}$ 27, in Figures 6 and 7, respectively. It can be seen that the profiles belonging to samples CA and MCN are very similar in both cases, highlighting again the similarity between both samples. Not only the shape of the peak, but also the characteristic temperatures (i.e. initial evolution temperature, maximum peak temperature, etc.) are almost identical for both samples. However, although sample MC has a similar volatile matter content to coal CA and light hydrocarbons are evolved during MC devolatilisation, their contributions to the $\mathrm{m} / \mathrm{z} 27$ and 30 signals are negligible or, at least, very small, as can be seen in Figures 6-7.

It has to be taken into account that in this work no calibration was performed to quantify the amount of each volatile species. Nevertheless, the ion signals given by the spectrometer were normalised by the total intensity and the sample mass to make the results internally consistent [33]. In this way, it was possible to compare the same $\mathrm{m} / \mathrm{z}$ signals for different samples; in addition the peak area from the different species profiles can be calculated, in order to provide a semi-quantitative analysis.

The peak area of the HCN and NO profiles were calculated. Those belonging to MC were 10 and $15 \%$, respectively, of the areas due to MCN. This means that the main contribution to these $\mathrm{m} / \mathrm{z}$ signals ( $\mathrm{m} / \mathrm{z} 27$, after CO correction, and $\mathrm{m} / \mathrm{z} 30$ ) was due to nitrogen volatile compounds and not to light hydrocarbons. Obviously, these are indicative percentages and 
cannot be used for a precise quantitative determination of the contributions of hydrocarbons to $\mathrm{m} / \mathrm{z} 27$ and 30 .

\section{CONCLUSIONS}

The $\mathrm{m} / \mathrm{z}$ signals from nitrogen volatile compounds (i.e. $\mathrm{m} / \mathrm{z} 14,27$ and 30) present interferences from other species evolved during coal devolatilisation, mainly $\mathrm{CO}, \mathrm{CH}_{4}$ and light hydrocarbons. It has been shown in this work that the contributions of $\mathrm{CO}$ and $\mathrm{CH}_{4}$ can be calculated and, after the application of correction factors, the evolution of some nitrogen species during coal devolatilisation can be followed by mass spectrometry. In addition, it was found that the contribution of light hydrocarbons to $\mathrm{m} / \mathrm{z} 27$ and 30 can be considered as negligible, even taking into account the high volatile matter content of the samples used in this work. It can be stated therefore that besides its other multiple applications, the TG-MS technique can be used to follow the evolution of nitrogen volatile compounds during coal devolatilisation.

\section{ACKNOWLEDGEMENTS}

Work carried out with a financial grant from the European Coal and Steel Community (Project 7220-PR-071). Support and the fellowship for C.P. from the Plan Regional de Investigación del Principado de Asturias is also acknowledged.

\section{REFERENCES}

1. P.R. Solomon and T.H. Fletcher, Twenty-Fifth Symposium (International) on Combustion/The Combustion Institute, 1994, p. 463.

2. Z. Wu and Y. Ohtsuka, Energy \& Fuels, 11 (1997) 477. 
3. K. Stanczyk and J.P. Boudou, Fuel, 73 (1994) 940.

4. D. Liu, Z. Wu, B. Shen, B. Fend and Z. Lin, Energy \& Fuels, 13 (1999) 1252.

5. J.A. Miller and C.T. Bowman, Prog. Energ. Combust. Sci., 15 (1989) 287.

6. S. Kambara, T. Takarada, Y. Yamamoto and K. Kato, Energy \& Fuels, 7 (1993) 1013.

7. A. Williams, M. Pourkashanian, J.M. Jones and L.J. Rowlands, J. Inst. Energ., 70 (1997) 102.

8. G.G. de Soete, Twenty Third Symposium (International) on Combustion/The Combustion Institute, 1990, p. 1257.

9. G.F. Krammer and A.F. Sarofim, Combust. \& Flame, 97 (1994) 118.

10. W. Wang, S.D. Brown, C.J. Hindmarsh and K.M. Thomas, Fuel, 9 (1994) 1381.

11. K.M. Thomas, Fuel, 76 (1997) 457.

12. J. Leppälahti and T. Koljonen, Fuel Process. Technol., 43 (1995) 1.

13. R. Bassilakis, Y. Zhao, P.R. Solomon and M.A. Serio, Energy \& Fuels, 7 (1993) 710. 
14. J. Friebel and R.F.W. Köpsel, Fuel, 78 (1999) 923.

15. J.J. Morelli, J. Anal. Appl. Pyrol., 18 (1990) 1.

16. T. Coll, J.F. Perales, J. Arnaldos and J. Casal, Thermochim. Acta, 196 (1992) 53.

17. W.A. Kneller, Thermochim. Acta, 108 (1986) 357.

18. M.V. Kök and M.R. Pamir, J. Anal. Appl. Pyrol., 35 (1995) 145.

19. P.R. Solomon, M.A. Serio and E.M. Suuberg, Prog. Energ. Combust. Sci., 18 (1992) 133.

20. W. Wanzl, Fuel Process. Technol., 20 (1988) 317.

21. S.S.J. Warne, Thermochim. Acta, 272 (1996) 1.

22. M.A. Wójtowicz, J.R. Pels and J.A. Moulijn, Fuel Process. Technol., 34 (1993) 1.

23. E. Jakab, F. Till and G. Várhegyi, Fuel Proc. Tech., 28 (1991) 221.

24. K. Kidena, Y. Hirose, T. Aibara, S. Murata and M. Nomura, Energy \& Fuels, 14 (2000) 184.

25. E.B. Ledesma, C.Z. Li, P.F. Nelson and J.C. Mackie, Energy \& Fuels, 12 (1998) 536. 
26. M. Herrera, G. Matuschek and A.A. Kettrup, J. Therm. Anal. Calorim., 59 (2000) 385.

27. P. Ehrburger and J. Dentzer, J. Anal. Appl. Pyrol., 24 (1993) 333.

28. J.P. Boudou, J. Bimer, P.D. Salbut, D. Cagniant and R. Gruber, Fuel, 6 (1994) 907.

29. O.C. Kopp and E.L. Fuller, Int. Conf. on Coal Sci., Vol. I (1993) p. 69.

30. G. Matuschek and A.A. Kettrup, J. Anal. Appl. Pyrol., 51 (1999) 223.

31. C.J. Hindmarsh, J.E. Varey and K.M. Thomas, Prep. ACS, 39, 3 (1994) 747.

32. J.E. Varey, C.J. Hindmarsh and K.M. Thomas, Fuel, 75 (1996) 164.

33. A. Arenillas, F. Rubiera and J.J. Pis, J. Anal. Appl. Pyrol., 50 (1999) 31.

34. J.M. Jones, A.W. Harding, S.D. Brown and K.M. Thomas, Carbon, 33 (1995) 833.

35. P. Painter, P. Opaprakasit, M. Sobkowiak and A. Scaroni, Prep. ACS, 44, 3 (1999) 596.

36. K.H. van Heek and W. Hodek, Fuel, 6 (1994) 886.

37. R.M. Davidson, Nitrogen in coal, IEA Perspectives, ISBN 92-9029-230-X, 1994, p. 12.

38. K. Stanczyk, Energy \& Fuels, 13 (1999) 82. 
39. I. Aarna and E.M. Suuberg, Energy \& Fuels, 13 (1999) 1145.

40. P. Chambrion, T. Kyotani and A. Tomita, Energy \& Fuels, 12 (1998) 416.

41. A.I. Vogel, in Practical Organic Chemistry Including Qualitative Organic Analysis, $3^{\text {rd }}$ Ed., Longmans, London, 1961, p. 1022.

42. I. Pitkänen, J. Huttunen, H. Halttunen, and R. Vesterien, J. Therm. Anal. Calorim., 56 (1999) 1253.

43. Nicolet Instrument Corp., IRTF TGA Vapor Phase Library, 1992. 
Table 1. MS signals followed during coal pyrolysis and their assignment to the main fragmented ions.

\begin{tabular}{|c|c|c|c|c|c|c|c|c|c|c|c|c|c|}
\hline $\mathrm{m} / \mathrm{z}$ & 2 & 12 & 14 & 15 & 16 & 17 & 18 & 26 & 27 & 28 & 30 & 41 & 44 \\
\hline \multirow{4}{*}{ 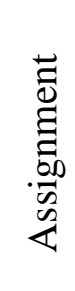 } & $\mathrm{H}_{2}^{+}$ & $\mathrm{C}^{+}$ & $\mathrm{N}^{+}$ & $\mathrm{CH}_{3}{ }^{+}$ & $\mathrm{CH}_{4}^{+}$ & $\mathrm{OH}^{+}$ & $\mathrm{H}_{2} \mathrm{O}^{+}$ & $\mathrm{CN}^{+}$ & $\mathrm{HCN}^{+}$ & $\mathrm{CO}^{+}$ & $\mathrm{NO}^{+}$ & \multirow[t]{4}{*}{$\mathrm{C}_{3} \mathrm{H}_{5}{ }^{+}$} & $\mathrm{CO}_{2}{ }^{+}$ \\
\hline & & & $\mathrm{N}_{2}{ }^{++}$ & & $\mathrm{O}^{+}$ & $\mathrm{NH}_{3}{ }^{+}$ & $\mathrm{NH}_{4}{ }^{+}$ & $\mathrm{C}_{2} \mathrm{H}_{2}{ }^{+}$ & $\mathrm{C}_{2} \mathrm{H}_{3}{ }^{+}$ & $\mathrm{C}_{2} \mathrm{H}_{4}{ }^{+}$ & \multirow[t]{3}{*}{$\mathrm{C}_{2} \mathrm{H}_{6}{ }^{+}$} & & $\mathrm{C}_{3} \mathrm{H}_{8}{ }^{+}$ \\
\hline & & & $\mathrm{CO}^{++}$ & & $\mathrm{O}_{2}^{++}$ & & & & & $\mathrm{N}_{2}^{+}$ & & & \multirow[t]{2}{*}{$\mathrm{N}_{2} \mathrm{O}^{+}$} \\
\hline & & & $\mathrm{CH}_{2}{ }^{+}$ & & & & & & & & & & \\
\hline
\end{tabular}

Table 2. MS signals detected and their relative intensities for different gaseous compounds.

\begin{tabular}{|c|c|c|c|c|c|c|c|}
\hline Compound & \multicolumn{7}{|c|}{$\begin{array}{l}\text { m/z signals } \\
\text { (relative intensities) }\end{array}$} \\
\hline \multirow{2}{*}{$\mathrm{CH}_{4}$} & 14 & 15 & 16 & & & & \\
\hline & (15) & (87) & (100) & & & & \\
\hline \multirow{2}{*}{$\mathrm{CO}$} & 12 & 14 & 16 & 18 & 27 & 28 & 29 \\
\hline & (4) & (1) & (2) & (1) & (1) & (100) & (1) \\
\hline \multirow{2}{*}{$\mathrm{CO}_{2}$} & 12 & 16 & 18 & 22 & 28 & 44 & \\
\hline & (8) & (14) & (1) & (2) & (12) & (100) & \\
\hline \multirow{2}{*}{$\mathrm{N}_{2}$} & 14 & 27 & 28 & 29 & & & \\
\hline & (11) & (1) & (100) & (1) & & & \\
\hline \multirow{2}{*}{$\mathrm{N}_{2} \mathrm{O}$} & 14 & 16 & 28 & 30 & 32 & 44 & \\
\hline & (15) & (6) & (19) & (37) & (1) & (100) & \\
\hline \multirow{2}{*}{$\mathrm{NO}$} & 14 & 15 & 16 & 18 & 28 & 30 & 32 \\
\hline & (7) & (4) & (2) & (2) & (4) & (100) & (2) \\
\hline
\end{tabular}


Table 3. Proximate and ultimate analyses of the CA coal and the model coals with (MCN) and without (MC) nitrogen in their composition, ( ${ }^{a}$ db: dry basis; ${ }^{b}$ : dry ash free basis; ${ }^{c}$ : calculated by difference).

\begin{tabular}{|c|c|c|c|c|c|c|c|}
\hline \multirow{2}{*}{ Sample } & \multicolumn{2}{|c|}{ Proximate analysis (wt\% $\mathrm{db}^{\mathrm{a}}$ ) } & \multicolumn{5}{|c|}{ Ultimate analysis (wt\% daf ${ }^{b}$ ) } \\
\hline & Volatile matter & Ash & $\mathrm{C}$ & $\mathrm{H}$ & $\mathrm{N}$ & $\mathrm{S}$ & $\mathrm{O}^{\mathrm{c}}$ \\
\hline CA & 37.5 & 7.3 & 84.9 & 5.5 & 1.9 & 1.5 & 6.2 \\
\hline MCN & 39.2 & - & 81.7 & 5.4 & 2.6 & - & 10.3 \\
\hline MC & 41.9 & - & 80.9 & 5.3 & - & - & 13.8 \\
\hline
\end{tabular}


Devolatilisation

Secondary Pyrolysis

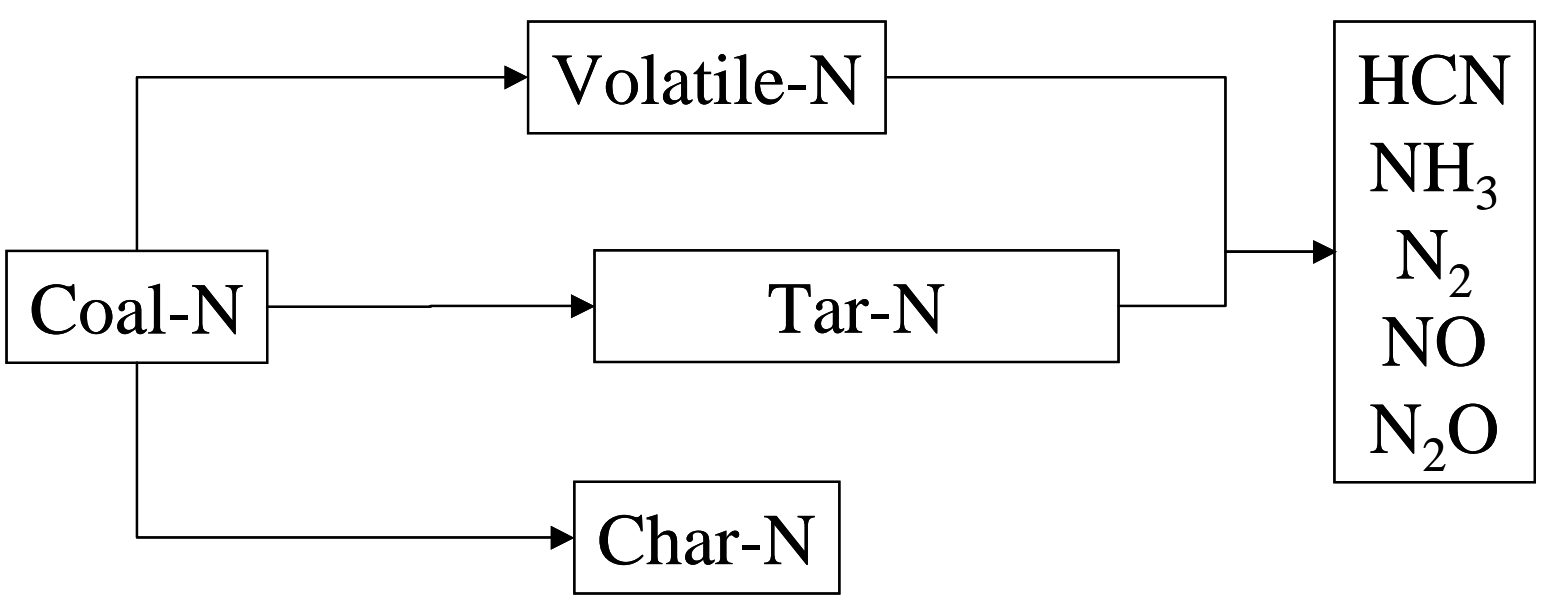

Figure 1. Scheme for nitrogen distribution during coal pyrolysis. 


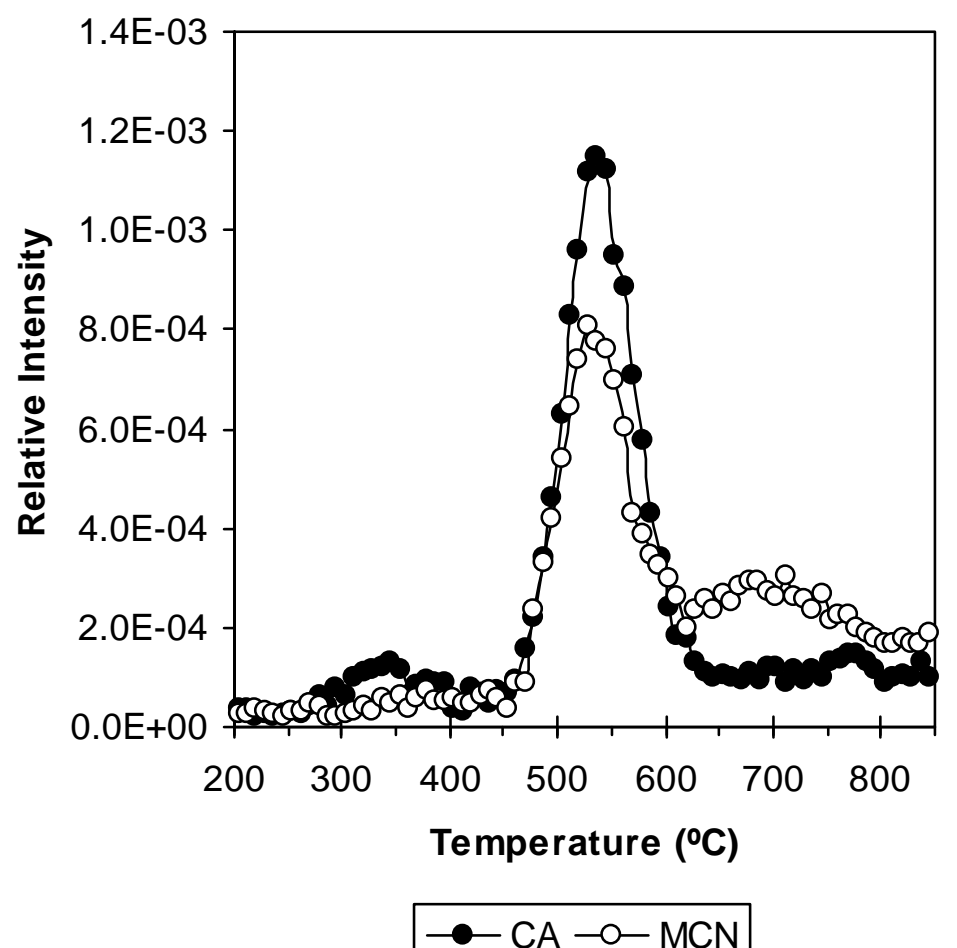

Figure 2. Evolution profiles of $\mathrm{m} / \mathrm{z} 41$ (light hydrocarbons) followed by MS during the pyrolysis of coals CA and MCN. 

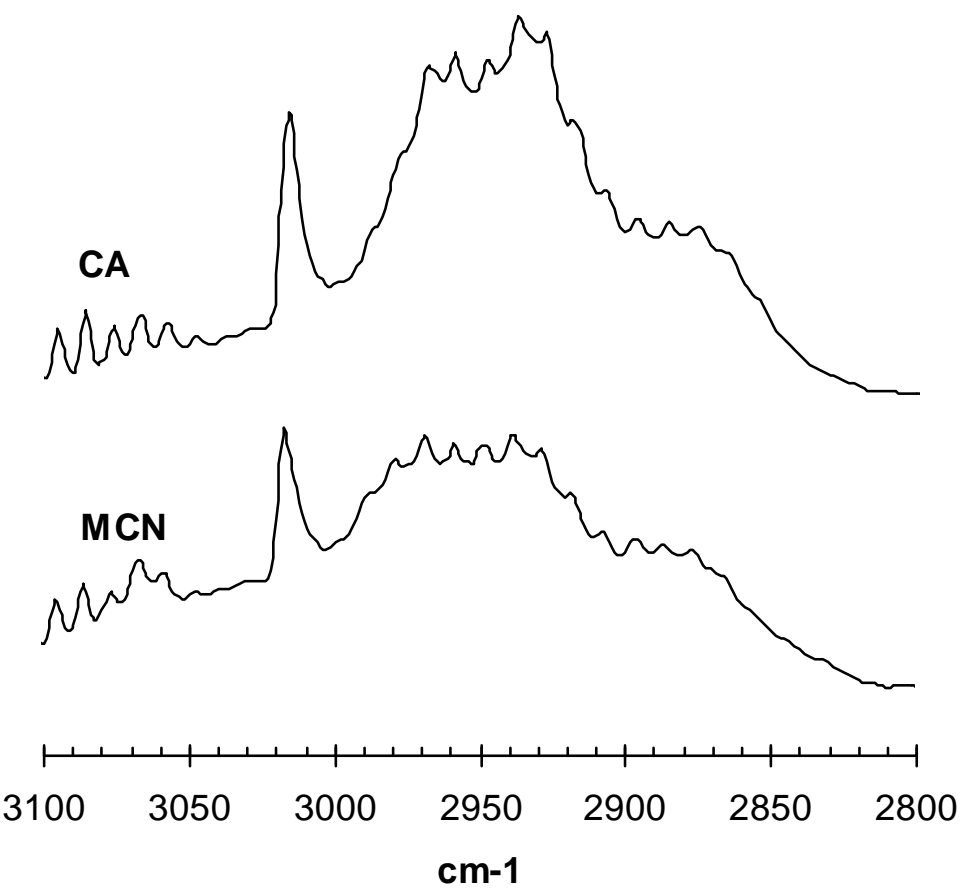

Figure 3. IRTF gas spectra of light hydrocarbons evolution during CA and MCN pyrolysis, at a temperature of around $450{ }^{\circ} \mathrm{C}$. 


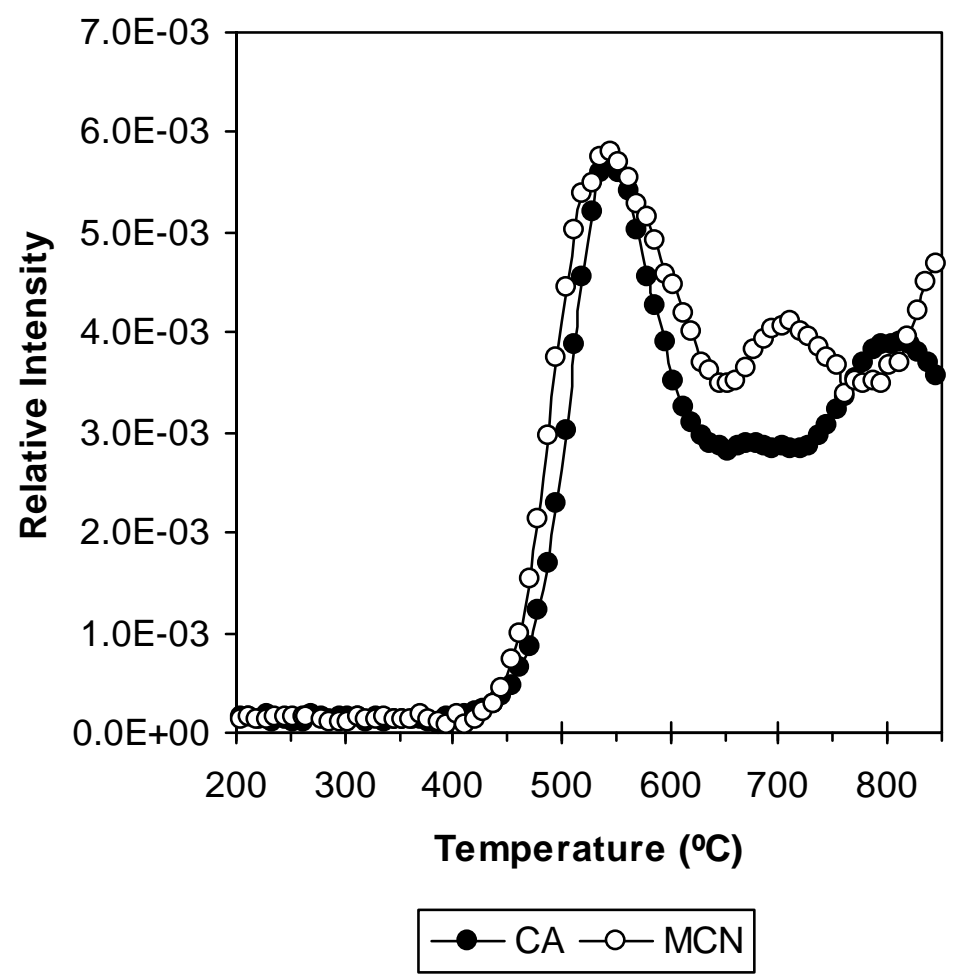

Figure 4. CO profile evolution (m/z 28) followed by MS during the pyrolysis of coals CA and MCN. 


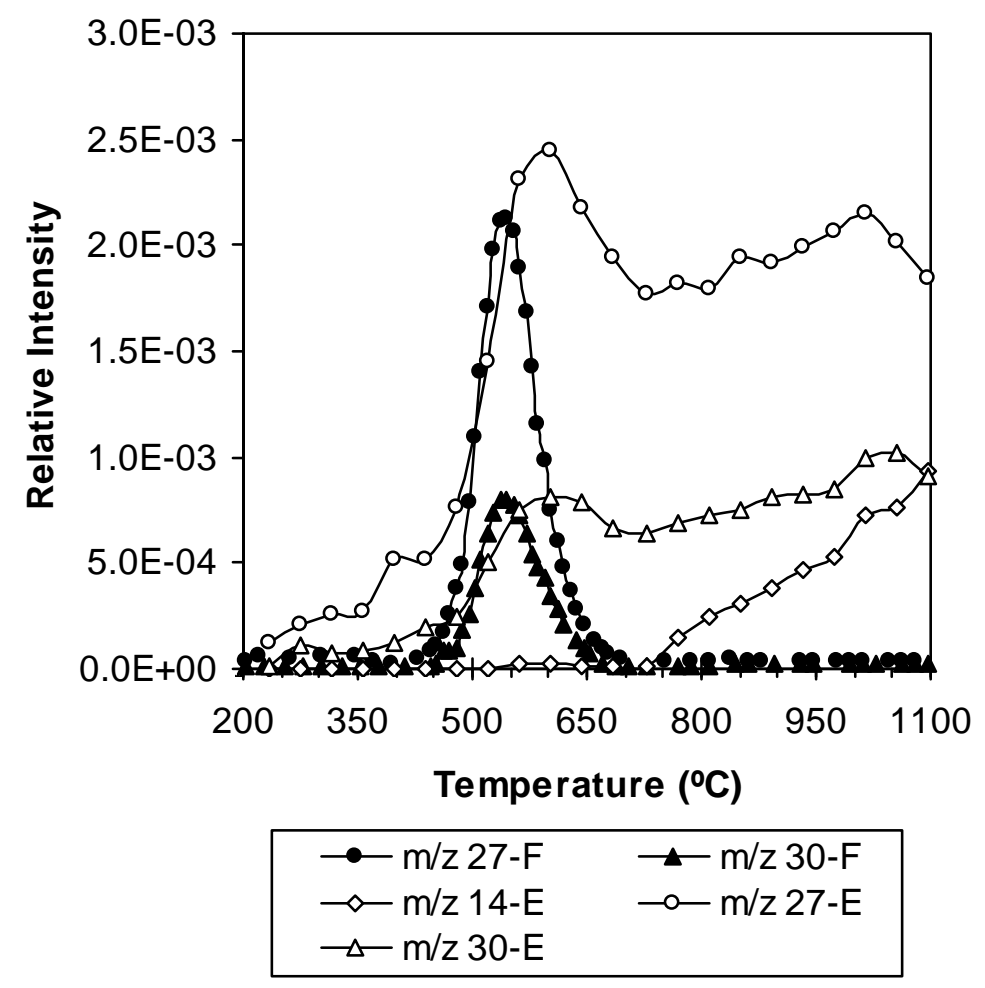

Figure 5. Evolution profiles of $\mathrm{m} / \mathrm{z} 14,27$ and $30\left(\mathrm{~N}_{2}^{++}, \mathrm{HCN}^{+}\right.$and $\mathrm{NO}^{+}$, respectively) followed by MS during the pyrolysis of coal CA with two TG-MS sampling systems: inside the furnace and close to the sample (F) and at the exit of the thermobalance (E). 


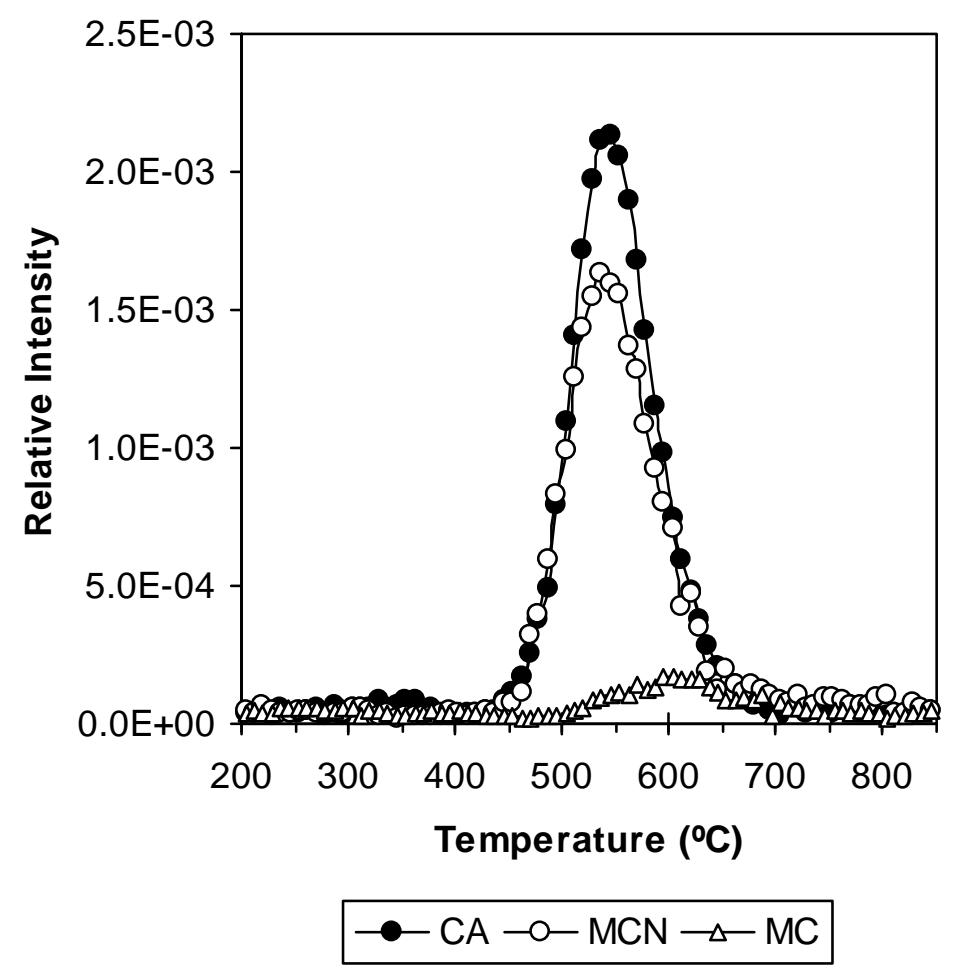

Figure 6. HCN evolution (m/z 27 after corrections) followed by MS during CA, MCN and MC pyrolysis. 


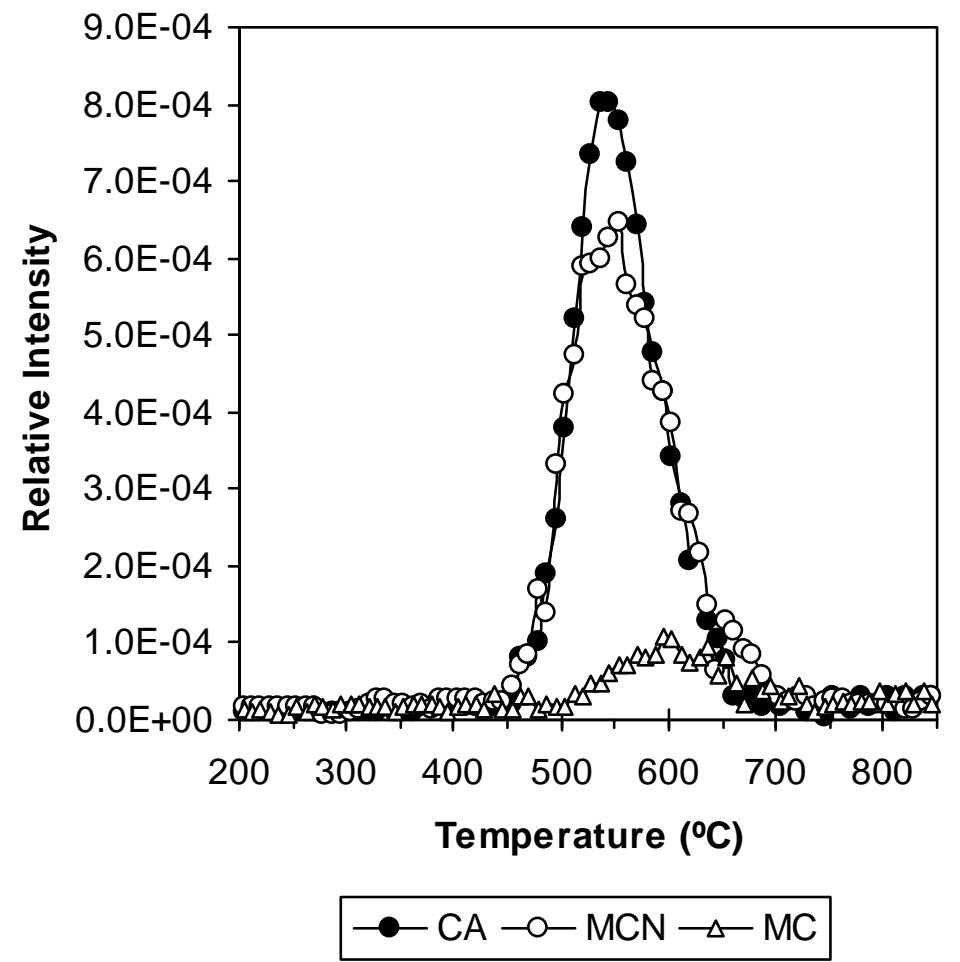

Figure 7. NO evolution followed by MS during CA, MCN and MC pyrolysis. 